UCRL-ID-120258

The Elevated Temperature Tensile Properties of S-200E Commercially Pure Beryllium

G. A. Henshall

S. G. Torres

J. E. Hanafee

March 1, 1995

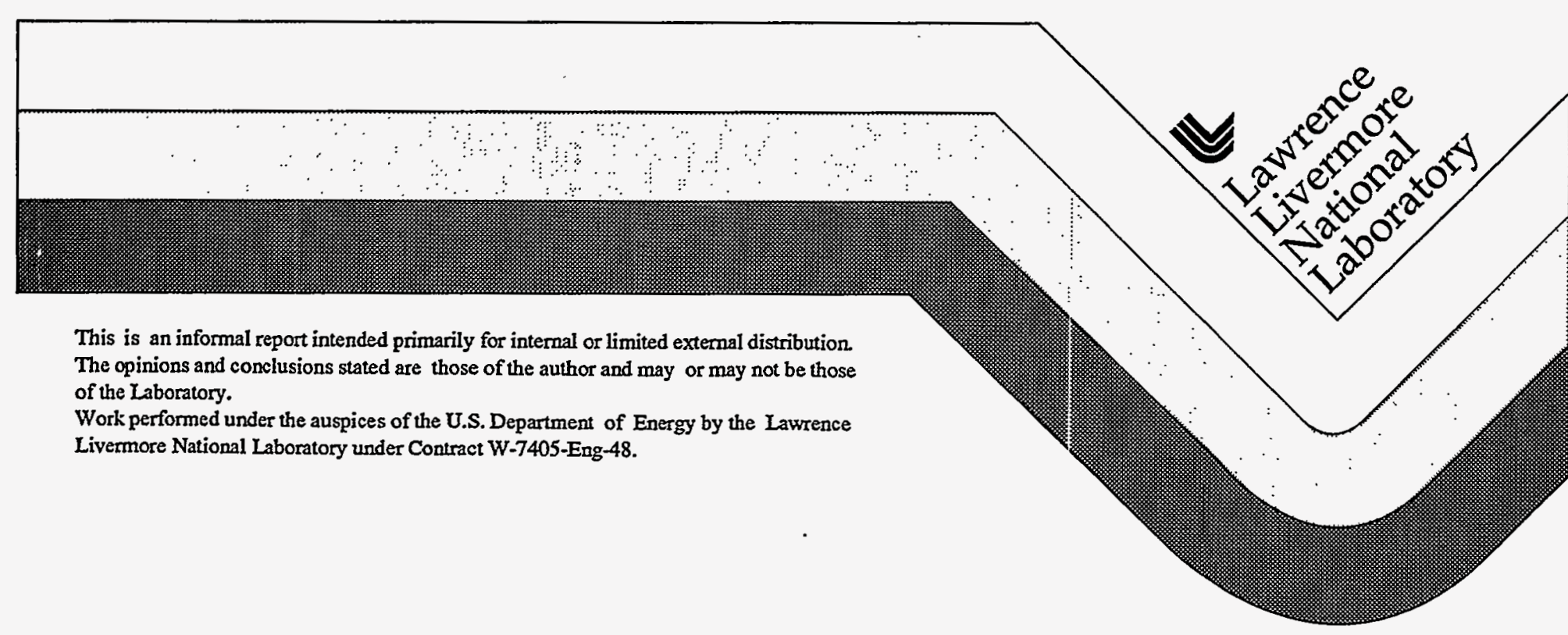




\section{DISCLATMER}

This document was prepared as an account of work sponsored by an agency of the United States Government. Neither the United States Government nor the University of California nor any of their employees, makes any warranty, express or implied, or assumes any legal liability or responsibility for the accuracy, completeness, or usefulness of any information, apparatus, product, or process disclosed, or represents that its use would not infringe privately owned rights. Reference herein to any specific commercial products, process, or service by trade name, trademark, manufacturer, or otherwise, does not necessarily constitute or imply its endorsement, recommendation, or favoring by the United States Government or the University of California. The views and opinions of authors expressed herein do not necessarily state or reflect those of the United States Government or the University of California, and shall not be used for advertising or product endorsement purposes.

This report has been reproduced directly from the best available copy.

Available to DOE and DOE contractors from the Office of Scientific and Technical Information P.O. Box 62, Oak Ridge, TN 37831

Prices available from (615) 576-8401, FTS 626-8401

Available to the public from the

National Technical Information Service

U.S. Department of Commerce 5285 Port Royal Rd.

Springfield, VA 22161 


\section{DISCLAIMER}

Portions of this document may be illegible in electronic image products. Images are produced from the best available original document. 


\title{
The Elevated Temperature Tensile Properties of S-200E Commercially Pure Beryllium
}

\author{
G. A. Henshall, S. G. Torres, and J. E. Hanafee
}

\begin{abstract}
The tensile properties of commercially pure beryllium are sensitive to temperature, impurity content, texture, grain size, and prior processing. Therefore, tensile tests have been conducted using the commercially pure S-200E Be commonly employed at Lawrence Livermore National Laboratory. These experiments were performed at temperatures ranging from 300 to $1100^{\circ} \mathrm{C}$ in the longitudinal and transverse orientations at the quasi-static strain rate of $5.5 \times 10^{-4} \mathrm{~s}^{-1}$.

The results of these experiments reveal that the stress-strain curve is smooth, i.e. without yield points or serrations, over the entire temperature range studied. The yield stress (YS) and ultimate tensile stress (UTS) decrease monotonically with increasing temperature. Similar strengths were measured for both the longitudinal and transverse orientations, with the latter exhibiting slightly lower YS and UTS values. The measured failure elongation $\left(e_{f}\right)$ vs. temperature curve is complex due to the competing effects of increasing basal-plane fracture stress with increasing temperature combined with the presence of hot shortness at intermediate temperatures. The latter is believed to be caused, at least partially, by the presence of free aluminum impurities at the grain boundaries. This hypothesis is supported by the measured increase in $e_{f}$ at $700{ }^{\circ} \mathrm{C}$ following a 100 -hr anneal at $750{ }^{\circ} \mathrm{C}$, which would remove free $\mathrm{Al}$ from the grain boundaries. Texture also was found to influence $e_{f}$ The favorable orientation of the basal planes for initiation and propagation of cleavage cracks in longitudinal specimens results in a significantly decreased failure elongation compared with the transverse orientation. The effects of testing temperature and specimen orientation on the reduction in area were
\end{abstract}


found to be similar to those described for $e_{f}$ Finally, comparison of the tensile results with the compression data of Abeln et al. suggests that the stress-strain response of S$200 \mathrm{E} B$ is not significantly affected by the direction of straining. The only exception to this finding is that serrated flow occurs in compression at $500{ }^{\circ} \mathrm{C}$, while the tension curves are smooth at all temperatures. The favorable comparison between the data of Abeln $e t a l$. and the present study also provides confidence in the results reported here.

\section{DISCLAIMER}

This report was prepared as an account of work sponsored by an agency of the United States Government. Neither the United States Government nor any agency thereof, nor any of their employees, makes any warranty, express or implied, or assumes any legal liability or responsibility for the accuracy, completeness, or usefulness of any information, apparatus, product, or process disclosed, or represents that its use would not infringe privately owned rights. Reference herein to any specific commercial product, process, or service by trade name, trademark, manufacturer, or otherwise does not necessarily constitute or imply its endorsement, recommendation, or favoring by the United States Government or any agency thereof. The views and opinions of authors expressed herein do not necessarily state or reflect those of the United States Government or any agency thereof. 


\section{Introduction}

Commercially pure beryllium is a commonly used structural material at Lawrence Livermore National Laboratory (LLNL). Design calculations involving Be typically include finite-element stress analyses using the NIKE [1] structural mechanics code. For the constitutive model most often used within NIKE for these purposes, the yield stress (YS), ultimate tensile stress (UTS), and elongation to failure $\left(e_{f}\right)$ all are needed at one or more quasi-static strain rate. These data are required over the entire range of temperatures to which the component may be exposed in service or in conceivable accident scenarios. Therefore, this full body of data must be available to the design engineer for the grade of Be used in the design.

The YS, UTS, and $e_{f}$ were not available in the literature over the temperature range of interest for the commercially pure S-200E Be employed at LLNL. Therefore, an experimental investigation of the elevated temperature tensile properties of S-200E Be was undertaken. These experiments were performed using the stock material employed at LLNL so that the data reflect the relevant impurity contents and processing methods. Further, since the mechanical properties of Be are known to be anisotropic [2,3], the tensile properties were evaluated for both the transverse and longitudinal orientations of the stock material. The results of these tests are presented in this report in such a way that the design engineer can make use of them in finite-element analyses.

\section{Experimental Materials and Procedures}

The commercially pure Be used in this investigation was Brush Wellman grade S-200E. This product is vacuum hot pressed from powder produced by the attrition method. Unlike some other grades of commercially pure $\mathrm{Be}$, no post-consolidation anneal is performed for S-200E [4]. The chemical composition specified for this material is given in Table I. As discussed elsewhere [3-6], the impurities most influential on the mechanical properties are $\mathrm{BeO}, \mathrm{Al}$, and $\mathrm{Fe}$. 
Table I. Specified chemical composition for S-200E beryllium.

\begin{tabular}{cc}
\hline Species & Content (wt. \%) \\
& Bal. \\
$\mathrm{Be}$ & 1.6 \\
$\mathrm{Fe}$ & 0.06 \\
$\mathrm{Al}$ & 0.03 \\
$\mathrm{C}$ & 0.08 \\
$\mathrm{Mg}$ & 0.01 \\
$\mathrm{Si}$ & 0.03 \\
\hline
\end{tabular}

The material used in this study was received as a 10 -in. (254-mm) diameter cylindrical billet with a length of $30 \mathrm{in}$. $(762 \mathrm{~mm})$. Metallographic sections were taken from the as-received billet in both the longitudinal and transverse orientations. The grain size and microstructure appeared to be identical for both orientations. The average grain size of the as-received material was approximately $27 \mu \mathrm{m}$, with a minimum of $6 \mu \mathrm{m}$ and a maximum of $45 \mu \mathrm{m}$. A network of small (about $1 \mu \mathrm{m}$ ) particles, presumably BeO, was observed in the microstructure. A small number of unidentified inclusions with a diameter of about $10 \mu \mathrm{m}$ also was observed. Annealing the material for $1 \mathrm{hr}$. at $700{ }^{\circ} \mathrm{C}$ did not alter the microstructure visibly.

Shoulder-grip tensile specimens were machined from the cylindrical billet by single-point turning followed by polishing of the gage section to remove tool marks. Standard practices for machining Be were employed to reduce surface damage. To verify that surface damage was not significant, some specimens were annealed for one hour at 
$700^{\circ} \mathrm{C}$ in argon and others were chemically milled by etching in a $70^{\circ} \mathrm{C}$ stirred solution of $750 \mathrm{ml} \mathrm{H}_{3} \mathrm{PO}_{4}$ (85\%), $71 \mathrm{~g} \mathrm{CrO}_{3}$ (99\%), $200 \mathrm{ml}$ deionized $\mathrm{H}_{2} \mathrm{O}$, and $30 \mathrm{ml} \mathrm{H}_{2} \mathrm{SO}_{4}$ (95 to $98 \%$ ) [7]. Specimens were etched to remove 0.002 to 0.004 in. (0.051 to 0.102 $\mathrm{mm}$ ) of material from the diameter of the gage section. Two specimen geometries were needed to keep the tensile loads within reasonable limits for the wide range of strengths exhibited over the 300 to $1100{ }^{\circ} \mathrm{C}$ temperature range. Figure 1 presents a schematic representations of these geometries. Specimens were machined from the billet with two orientations: (1) longitudinal, with the axis of the specimen parallel to the long axis of the billet, and (2) transverse, with the specimen axis perpendicular to the long axis of the billet. Note that the $\{0001\}$ basal planes of the Be unit cell tend to be perpendicular to the axis of the billet in this textured product.

The equipment and procedures used to perform the experiments were described in detail by Torres and Henshall [8], and are summarized briefly here. Tensile testing was performed using a Brew Front-Loading, high vacuum furnace that was mounted between the columns of a screw-driven Instron Model TT-D-L universal testing machine. The temperature was measured using two type $\mathrm{S}$ thermocouples $(\mathrm{Pt} / \mathrm{Pt}-10 \% \mathrm{Rh})$ attached to the gage section of the specimen approximately 0.25 inches apart with 0.020 gauge niobium wire. Figure 2 presents a photograph showing the shoulder-grip specimen within the TZM molybdenum grips, the two thermocouples (prior to placement on the sample), the TZM molybdenum pull rods, and the tungsten furnace elements and shielding. Prior to heat-up and testing, the furnace was evacuated to a pressure of approximately $5 \times 10^{-5}$ torr. In cases for which an inert gas was used, the furnace was purged twice with house argon prior to final evacuation and filling with the desired gas. Tests were performed at a crosshead speed of $0.02 \mathrm{in} / \mathrm{min}$., corresponding to a strain rate of approximately $5.5 \times 10^{-4} \mathrm{~s}^{-1}$. Testing at other rates was beyond the scope of this investigation; the reader is referred to the work of Abeln et al. [4] for information on the strain-rate dependence of the flow stress for S-200E Be measured in compression. 
Load vs. time data were collected using a Hewlett-Packard data acquisition system. These load and displacement measurements were used to calculate and plot the stress vs. strain results, from which YS ( $0.2 \%$ offset from the elastic line), UTS, and $e_{f}$ values were determined. In addition, reduction-in-area measurements were performed by measuring the specimen diameter at three different positions (approximately $120^{\circ}$ apart) on each half of the fractured specimens using an optical comparator. An average value was used to compute the reduced cross-sectional area at fracture. Finally, for tests in which a clear fracture load was detectable from the load-displacement curve (generally $T$ $\leq 600^{\circ} \mathrm{C}$ ) the fracture stress was computed by dividing the fracture load by the reduced area at fracture.

\section{Experimental Results and Discussion}

To test the possible influence of furnace atmosphere and tensile specimen preparation methods on the elevated temperature tensile properties of $\mathrm{Be}$, a small number of tests were performed in the intermediate temperature range of $500-800{ }^{\circ} \mathrm{C}$. In this temperature regime the failure elongations are relatively low and, therefore, the tensile properties are most sensitive to the potentially detrimental effects of specimen preparation and furnace atmosphere. Figure 3 shows that the specimen preparation method has little influence on the measured YS. A similarly small effect on the UTS also was observed. Figure 4 reveals that the variation in the measured $e_{f}$ is significantly larger than that for the strength values, with the annealed specimens consistently exhibiting the largest elongations. However, this finding may not be associated with the "healing" of surface damage but rather a decrease in the amount of free aluminum at grain boundaries caused by annealing [5], as discussed later in this section.

The insensitivity of the tensile results to the surface preparation after machining may be due to the absence of significant machining damage. In addition, the temperature range examined in this study, 300 to $1100{ }^{\circ} \mathrm{C}$, lies above the ductile-brittle transition 
temperature (DBTT); measurements by Abeln et al. [4] show that the DBTT for a similar grade of $\mathrm{Be}$ is $100-200^{\circ} \mathrm{C}$. Surface damage would be expected to significantly influence the tensile properties only below the DBTT. The main point from Fig. 4 is that etching the specimens prior to testing does not improve the elevated temperature ductility. Based on the results shown in Figs. 3 and 4, subsequent testing was performed using only asmachined specimens.

The effects of furnace atmosphere on the elevated temperature tensile properties of S-200E beryllium are illustrated in Figs. 5 and 6. Figure 5 summarizes the YS data for as-machined, longitudinal specimens tested in house argon (purity not known precisely),

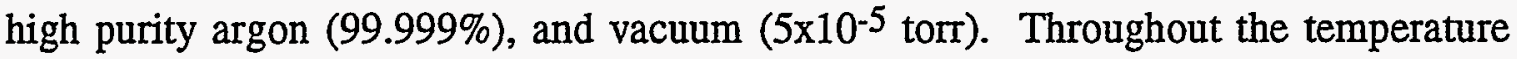
range studied, there is only a small variation in YS for the various furnace atmospheres. Although these limited data may support a small systematic decrease in YS for specimens tested in vacuum, the deviations are within experimental error, about 15-20\%. Similar results were obtained for the UTS. Figure 6 shows that the effects of furnace atmosphere on ductility are not systematic. The relatively large scatter in these data is typical for $e_{f}$ measurements in $\mathrm{Be}$ [9]. In summary, the furnace atmosphere was not found to have a significant influence on the elevated temperature tensile properties of Be. This finding is consistent with previous studies showing that oxygen, nitrogen, and hydrogen impurities do not have a large effect on the mechanical properties of $\mathrm{Be}[5,9]$.

Tensile tests of S-200E beryllium in the longitudinal and transverse orientations were then performed over the entire temperature range $\left(300-1100^{\circ} \mathrm{C}\right)$ using specimens in the as-machined condition and a high purity argon atmosphere. These data are tabulated in the Appendix. All of the measured stress-strain curves were smooth, with no indications of a yield point or serrated flow. The lack of a yield point in S-200E is consistent with the compression data of Abeln et al. [4] for this grade of Be. It is also consistent with the lack of a post-consolidation anneal which could result in the pinning of dislocations by solute diffusion and/or precipitation [4]. Unlike the finding of the 
present study, Abeln et al. found evidence for serrated yielding in compression at $500{ }^{\circ} \mathrm{C}$. However, they noted that the results of earlier tensile studies are consistent with our observation of a lack of serrated flow at $500{ }^{\circ} \mathrm{C}$. No explanation currently exists to explain this difference in the tension and compression data [4].

Quantitative comparisons of the tensile stress-strain curves with compression data gathered by Abeln et al. [4] at Rocky Flats Plant (RFP) also have been made. Figures 7 and 8 compare our $5.5 \times 10^{-4} \mathrm{~s}^{-1}$ results at 400 and $500^{\circ} \mathrm{C}$ with the RFP data of Abeln $e t$ $a l$. at the similar strain rate of $1.0 \times 10^{-3} \mathrm{~s}^{-1}$. Figure 7 shows that there is relatively little scatter in the LLNL data at $400{ }^{\circ} \mathrm{C}$, and that the tensile results are similar to those in compression. Figure 8 shows a favorable comparison of the two data sets at $500^{\circ} \mathrm{C}$. For both temperatures, the "flattening" of the tensile curves near the highest strains is associated with plastic instability in tension, and does not indicate a true difference in material behavior compared with compression loading. The compression tests do not suffer from this instability, and the flow stress rises continuously to true strains as large as 0.8 [4]. For lower strains, the tensile flow stress is somewhat larger than the compression flow stress at both temperatures. However, this deviation is small considering the differences in testing methods (aside from the loading direction). Therefore, the data suggest that the flow stress of polycrystalline S-200E beryllium is not significantly affected by the direction of loading.

The temperature dependence of the tensile properties for S-200E beryllium is presented in Figs. 9-14 for both orientations. (Note that no experiments were performed below $300^{\circ} \mathrm{C}$ in the present study; the $20^{\circ} \mathrm{C}$ data shown in Figs. 9-12 represent values certified by Brush Wellman and are shown only for reference.) Typical of a pure metal, both the YS and UTS decrease monotonically with increasing test temperature. Figures 9 and 10 show that the strength of S-200E beryllium in the transverse orientation generally is slightly less than that for the longitudinal orientation. The overall shapes of the YS and UTS vs. temperature curves are similar for the two orientations. Although elevated 
temperature tensile data are not available in the literature for S-200E beryllium, some data are available for other grades of vacuum hot pressed commercially pure material. The strength values we have obtained are consistent with these previous investigations [6]. In addition, the compression YS vs. temperature data of Abeln et al. [4] for S-200E in the longitudinal orientation are generally consistent with those presented in Fig. 9. While the compression values fall approximately $10 \%$ below those given in Fig. 9 for intermediate temperatures, the shape of the YS vs. temperature curve is the same for both investigations.

Compared with the strength data, a much more striking difference in properties between the longitudinal and transverse orientations is exhibited by the tensile failure elongations, Figs. 11 and 12. Again, the shapes of the ductility vs. temperature curves are similar, but the elongations are consistently larger for the transverse orientation. This result is not surprising since the basal planes are more favorably oriented for the initiation and propagation of cleavage cracks in the longitudinal orientation [2,3]. The complex shape of the $e_{f}$ vs. temperature curves is believed to be associated with the natural increase in the fracture stress of the $\{0001\}$ basal planes with increasing temperature [3] combined with hot shortness at intermediate temperatures caused by the presence of $\mathrm{Al}$ impurities, discussed below.

The S-200E beryllium used in this study contains about $300 \mathrm{ppm} \mathrm{Al}$ and $600 \mathrm{ppm}$ Fe (Table I). Al is known to cause hot shortness of beryllium at intermediate temperatures if it is present at the grain boundaries in elemental, i.e. "free," form [5]. The usual remedy for this problem is to anneal the material at temperatures of $650-800^{\circ} \mathrm{C}$ for roughly 60-200 hours, allowing for diffusion and the formation of $\mathrm{AlFeBe}_{4}$ precipitates upon reaction with Fe. (This may help to explain the higher ductilities in the annealed material in Fig. 4). To test this hypothesis, a longitudinal S-200E beryllium specimen was annealed in Ti foil for $100 \mathrm{~h}$ at $750{ }^{\circ} \mathrm{C}$. This specimen was tensile tested at $700{ }^{\circ} \mathrm{C}$ and the nominal strain rate of $5.5 \times 10^{-4} \mathrm{~s}^{-1}$. As shown in Figs. 9 and 10, annealing 
reduced the strength of the longitudinally oriented material somewhat; the YS and UTS values are similar to those of the unannealed transverse material. Similarly, Fig. 11 shows that the annealing treatment has increased the tensile elongation to a value more consistent with the unannealed transverse material. Therefore, it appears that the limited ductility of S-200E Be at intermediate temperatures may be caused, at least partially, by the presence of free $\mathrm{Al}$ at the grain boundaries.

The temperature dependence of the reduction in area (R. A.) is shown in Fig. 13 for S-200E Be in the longitudinal and transverse orientations. The trends exhibited in Fig. 13 are the same as those shown in Fig. 12 for $e_{f}$ The reduction in area increases from $300^{\circ} \mathrm{C}$ to a local maximum at $400{ }^{\circ} \mathrm{C}$, then decreases to a local minimum at 700 $800{ }^{\circ} \mathrm{C}$. Above $800{ }^{\circ} \mathrm{C}$, the reduction in area rapidly increases with increasing temperature to the highest temperature tested, $1100{ }^{\circ} \mathrm{C}$. Also consistent with the $e_{f}$ data, the reduction in area for the transverse orientation is generally larger than for the longitudinal orientation.

At high temperatures, typically $700{ }^{\circ} \mathrm{C}$ and above, the precise fracture load was not detectable from the digitized load vs. displacement data due to the gradual drop in load nearly to zero prior to specimen failure. However, for $300 \leq T \leq 600^{\circ} \mathrm{C}$ specimens typically fractured abruptly, allowing for unambiguous measurement of the fracture load. The fracture stress (FS), calculated from this load and the cross-sectional area at fracture, is shown in Fig. 14 as a function of temperature. For clarity, only the transverse data are compared with the corresponding UTS values; similar results were obtained for the longitudinal orientation, as tabulated in the Appendix. The data in Fig. 14 reveal that the fracture stress is significantly larger than the UTS for temperatures below $600^{\circ} \mathrm{C}$. Above $600{ }^{\circ} \mathrm{C}$, the fracture stress may be expected to nearly equal the UTS based on the trend shown in Fig. 14. However, additional data would be required to confirm this hypothesis. 


\section{Conclusions}

Based on the results of elevated temperature $\left(300\right.$ to $\left.1100{ }^{\circ} \mathrm{C}\right)$ tensile tests using commercially pure S- $200 \mathrm{E}$ beryllium, the following conclusions have been reached.

1. The furnace atmosphere (vacuum, low purity or high purity argon) and the specimen preparation procedures do not significantly affect the elevated temperature tensile properties of S-200E Be.

2. The stress-strain curves for S-200E tested in tension in the temperature range 300 to $1100{ }^{\circ} \mathrm{C}$ are smooth, with no yield points or serrated flow.

3. The yield stress (YS) and ultimate tensile stress (UTS) decrease monotonically with increasing temperature. Similar strengths were measured for both the longitudinal and transverse orientations, with the latter exhibiting slightly lower YS and UTS values.

4. The failure elongation $\left(e_{f}\right)$ vs. temperature curve is complex due to the competing effects of an increase in $\{0001\}$ basal-plane fracture stress with increasing temperature combined with hot shortness at intermediate temperatures. The latter is believed to be caused, at least partially, by the presence of free aluminum impurities at the grain boundaries. This hypothesis is supported by the measured increase in $e_{f}$ at $700{ }^{\circ} \mathrm{C}$ following a 100 -hr anneal at $750^{\circ} \mathrm{C}$, which would remove free $\mathrm{Al}$ from the grain boundaries.

5. The favorable orientation of the basal planes for initiation and propagation of cleavage cracks in longitudinal specimens results in a significantly decreased failure elongation compared with the transverse orientation.

6. The reduction-in-area data exhibit the same trends as a function of testing temperature and specimen orientation as measured for $e_{f}$

7. The fracture stress is significantly larger than the UTS for temperatures below about $600{ }^{\circ} \mathrm{C}$. Above this temperature, the data suggest that the fracture stress may nearly equal the UTS, though this conclusion has not been confirmed. 
8. Comparison of the tensile results with the compression data of Abeln et al. suggests that the flow stress of S-200E Be is not significantly affected by the direction of straining.

\section{References}

1) B. E. Engelmann, "NIKE2D User Manual," University of California - Lawrence Livermore National Laboratory, UCRL-MA-105413 (1991).

2) F. Aldinger, "Flow and Fracture of Single Crystals," in Beryllium Science and Technology, Vol. I, D. Webster and G. J. London, eds., Plenum Press, New York, pp. 7114 (1979):

3) H. J. Saxton and G. J. London, "Flow and Fracture of Polycrystalline Beryllium," in Beryllium Science and Technology, Vol. 1, D. Webster and G. J. London, eds., Plenum Press, New York, pp. 115-144 (1979).

4) S. P. Abeln, M. C. Mataya, and M. P. Riendeau, "Elevated Temperature Stress-Strain Behavior of Beryllium Powder Product," EG\&G, Rocky Flats Plant Report, September, 1994.

5) A. J. Stonehouse, "Impurity Effects in Beryllium," in Beryllium Science and Technology, Vol. I, D. Webster and G. J. London, eds., Plenum Press, New York, pp. 181-206 (1979).

6) N. R. Borch, "Elevated Temperature Behavior," in Beryllium Science and Technology, Vol. 1, D. Webster and G. J. London, eds. Plenum Press, New York, p.307330 (1979).

7) A. Goldberg, J. E. Hanafee, and R. G. Scott, "Mechanical Properties Evaluation of Some Commercial Beryllium Materials," University of California Lawrence Livermore National Laboratory Report No. UCRL-87392 (1982). 
8) S. G. Torres and G. A. Henshall, "Tensile Properties of 21-6-9 Stainless Steel at Elevated Temperature," University of California - Lawrence Livermore National Laboratory Report, UCRL-ID-114590 (1993).

9) Private communication with D. Crooks, Lockheed Palo Alto Research Laboratory, February 1994. 


\section{Appendix: Tabulated Data}

Table A.1. Tensile data for longitudinal, as-machined S-200E Be.

$\underline{\text { Temp. }\left({ }^{\circ} \mathrm{C}\right)} \underline{\text { YS (MPa) }} \quad \underline{\mathrm{UTS}(\mathrm{MPa})} \quad e_{f}(\%) \quad \underline{\text { R.A. (\%) }} \quad \underline{\text { FS (MPa) }}$

\begin{tabular}{|c|c|c|c|c|c|}
\hline 300 & 219.8 & 304.8 & 5.300 & 9.2 & 328.7 \\
\hline 300 & 202.4 & 294.8 & 9.950 & 16.9 & 333.0 \\
\hline 400 & 193.8 & 258.8 & 15.80 & 32.2 & 323.1 \\
\hline 400 & 203.8 & 261.8 & 13.15 & - & ----- \\
\hline 500 & 185.9 & 230.4 & 12.53 & 22.9 . & 255.9 \\
\hline 600 & 159.6 & 181.4 & 6.380 & 8.5 & 177.3 \\
\hline 600 & 142.4 & 159.6 & 4.150 & --.-- & --.- \\
\hline 600 & 161.1 & 185.9 & 6.580 & --- & ---- \\
\hline 700 & 122.4 & 127.4 & 3.270 & 4.0 & 107.7 \\
\hline 700 & 96.30 & 102.7 & 4.080 & 2.4 & 104.9 \\
\hline 700 & 112.9 & 117.9 & 2.990 & 3.7 & --- \\
\hline 800 & 52.21 & 53.00 & 3.620 & 3.9 & -- \\
\hline 800 & 34.30 & 34.80 & 4.020 & 1.2 & ---- \\
\hline 800 & 48.20 & 48.20 & 2.100 & 4.0 & -..- \\
\hline 900 & 15.39 & 15.70 & 8.480 & --- & ---- \\
\hline 1000 & 6.670 & 6.990 & 15.98 & 35.3 & ----- \\
\hline 1000 & 2.860 & 3.070 & 55.43 & 37.8 & ----- \\
\hline 1100 & 2.600 & 2.640 & 64.80 & 45.3 & $-\cdots$ \\
\hline
\end{tabular}


Table A.2. Tensile data for transverse, as-machined S-200E Be.

$\underline{\text { Temp. }\left({ }^{\circ} \mathrm{C}\right)} \underline{\underline{\mathrm{YS}(\mathrm{MPa})}} \quad \underline{\mathrm{UTS}(\mathrm{MPa})} \quad e_{f} \underline{(\%)} \quad \underline{\text { R.A. (\%) }} \quad \underline{\text { FS (MPa) }}$

$\begin{array}{lccccc}300 & 197.3 & 297.3 & 25.40 & 39.4 & 413.8 \\ 400 & 183.9 & 248.8 & 30.40 & , 45.7 & 333.4 \\ 500 & 162.6 & 196.4 & 15.16 & 29.6 & 237.1 \\ 500 & 158.1 & 189.6 & 14.73 & 22.6 & 222.0 \\ 600 & 155.1 & 185.1 & 9.890 & 18.9 & 202.2 \\ 700 & 59.95 & 60.45 & 8.870 & 5.1 & ---- \\ 700 & 59.45 & 60.45 & 5.340 & 3.8 & ---- \\ 700 & 57.96 & 59.45 & 5.820 & 5.1 & ---- \\ 800 & 20.73 & 21.10 & 6.580 & 5.8 & ---- \\ 900 & 7.990 & 8.040 & 15.18 & 15.0 & ---- \\ 1000 & 2.560 & 2.900 & 60.33 & 39.9 & --- \\ 1100 & 0.6900 & 0.7200 & 114.0 & 57.6 & ---- \\ 1100 & ----- & ----- & ---- & 63.6 & ----\end{array}$




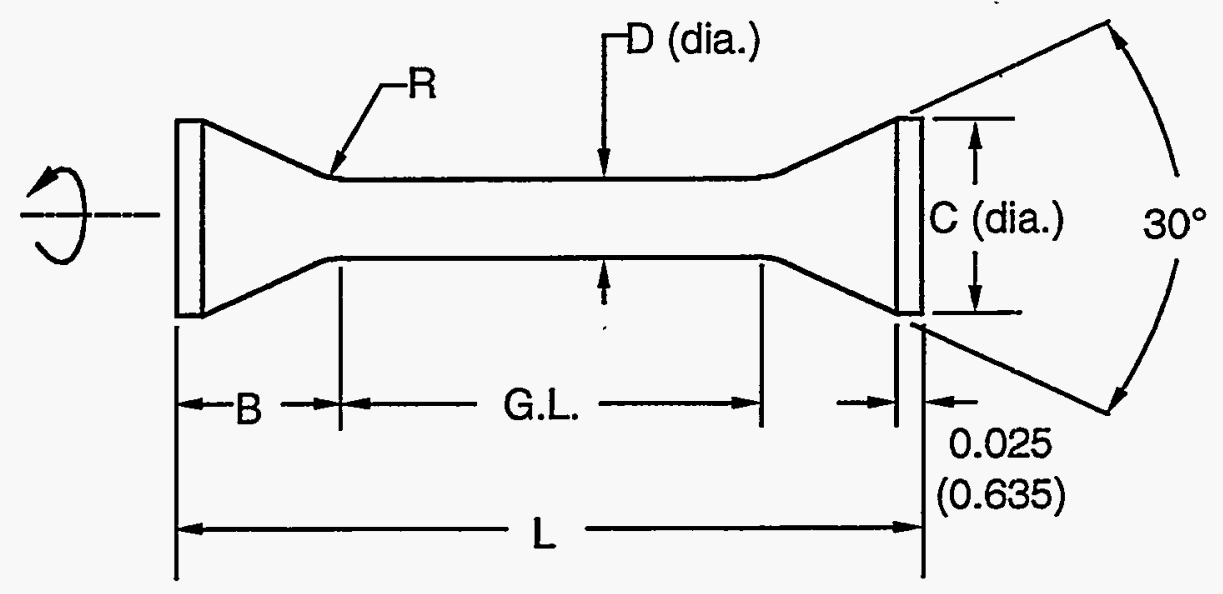

\begin{tabular}{|c|c|c|c|c|c|c|}
\hline Specimen & $\mathrm{D}$ & $\mathrm{R}$ & $\mathrm{G} . \mathrm{L}$. & $\mathrm{L}$ & $\mathrm{B}$ & $\mathrm{C}$ \\
\hline Low T & 0.134 & 0.241 & 0.595 & 1.195 & 0.300 & 0.286 \\
& $(3.40)$ & $(6.12)$ & $(15.11)$ & $(30.35)$ & $(7.62)$ & $(7.26)$ \\
\hline High T & 0.250 & 0.375 & 0.600 & 1.570 & 0.485 & 0.470 \\
& $(6.35)$ & $(9.52)$ & $(15.24)$ & $(39.88)$ & $(12.32)$ & $(11.94)$ \\
\hline
\end{tabular}

Figure 1. Schematic diagram of the cylindrical tensile specimen geometries for "low" temperature $\left(T \leq 900^{\circ} \mathrm{C}\right)$ and "high" temperature $\left(T>900^{\circ} \mathrm{C}\right)$ testing. Dimensions are given in inches with the $\mathrm{mm}$ equivalents in parentheses. 


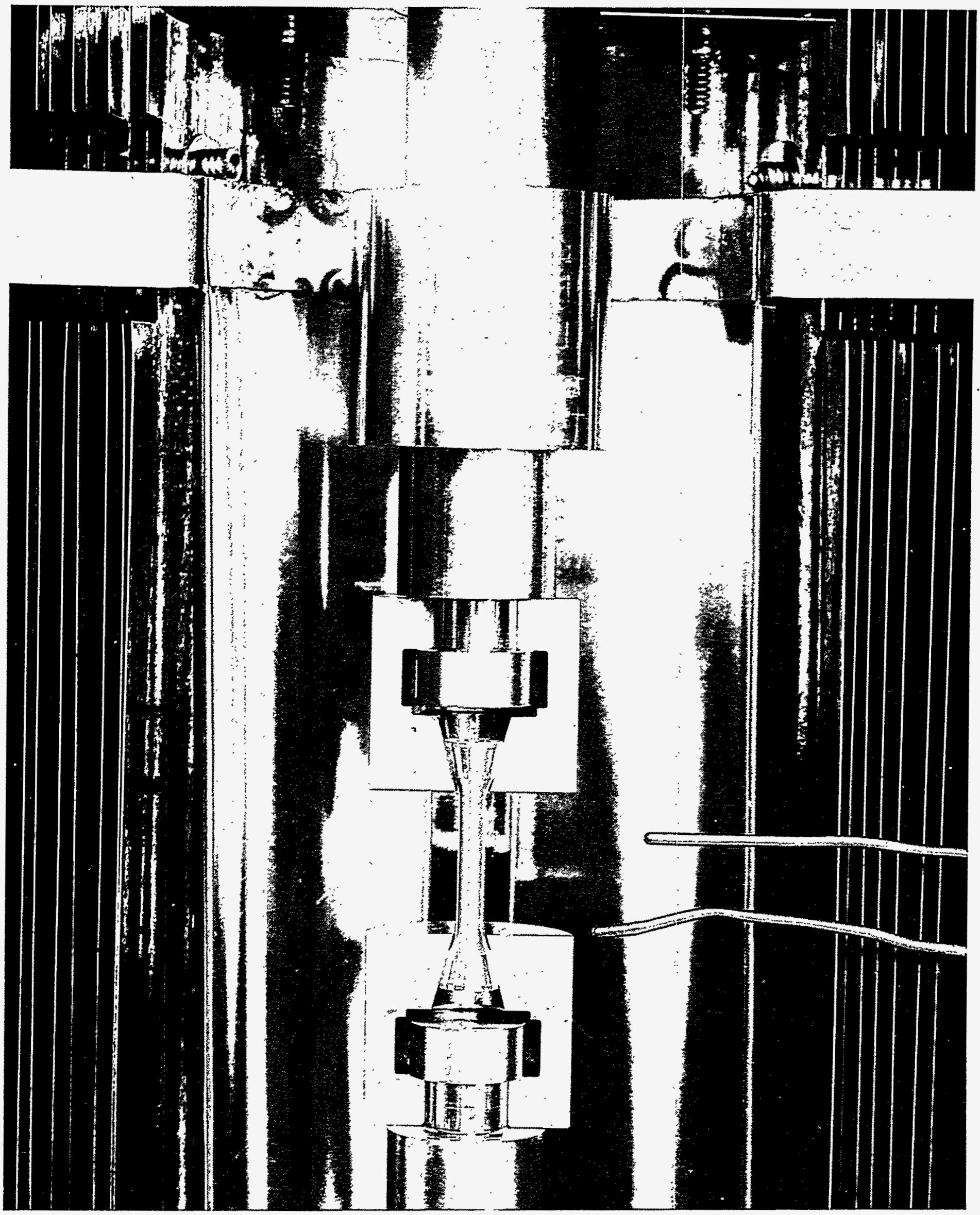

Figure 2. Photograph of the load train showing the furnace elements and shielding, grips, thermocouples, and shoulder-grip tensile specimen. 


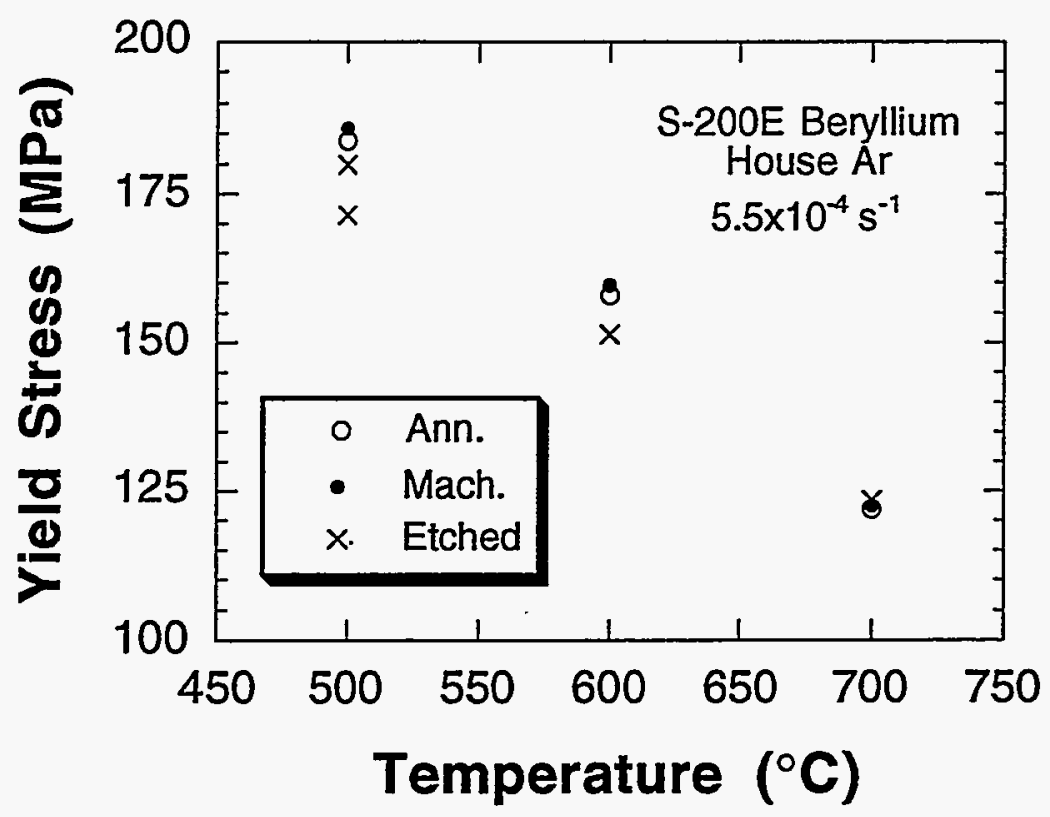

Figure 3. The effect of specimen preparation method on the yield stress of longitudinal $\mathrm{S}-200 \mathrm{E}$ Be at intermediate temperatures.

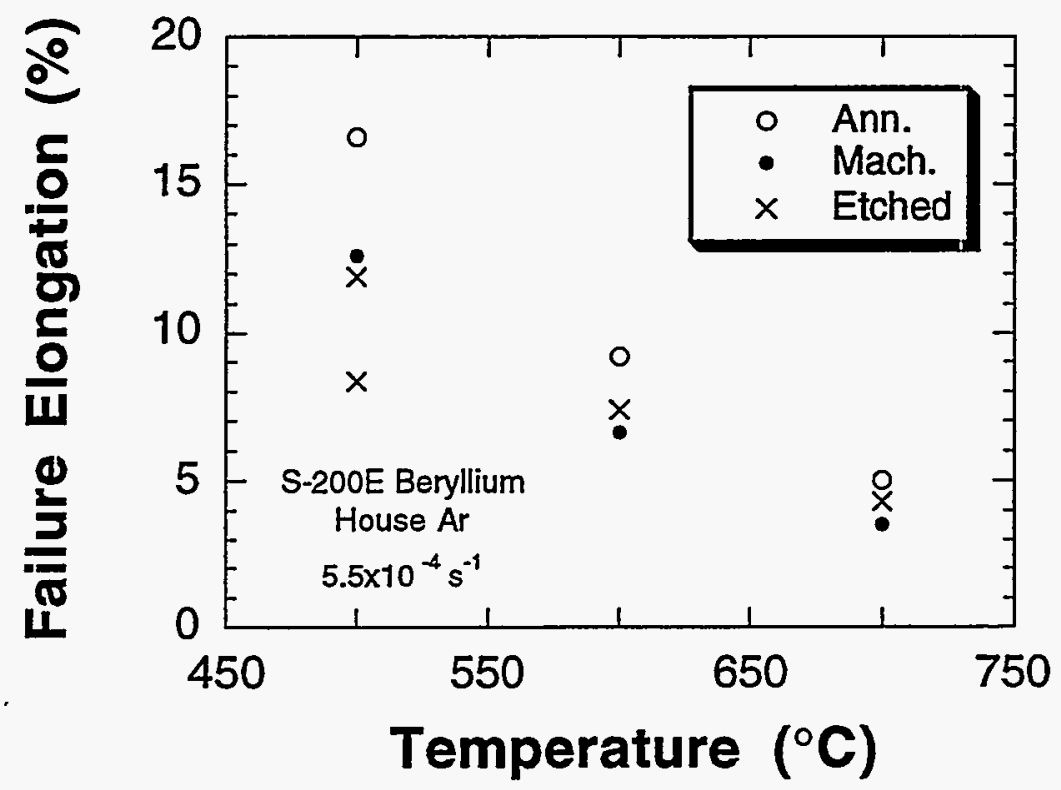

Figure 4. The effect of specimen preparation method on the failure elongation of longitudinal S-200E Be at intermediate temperatures. 


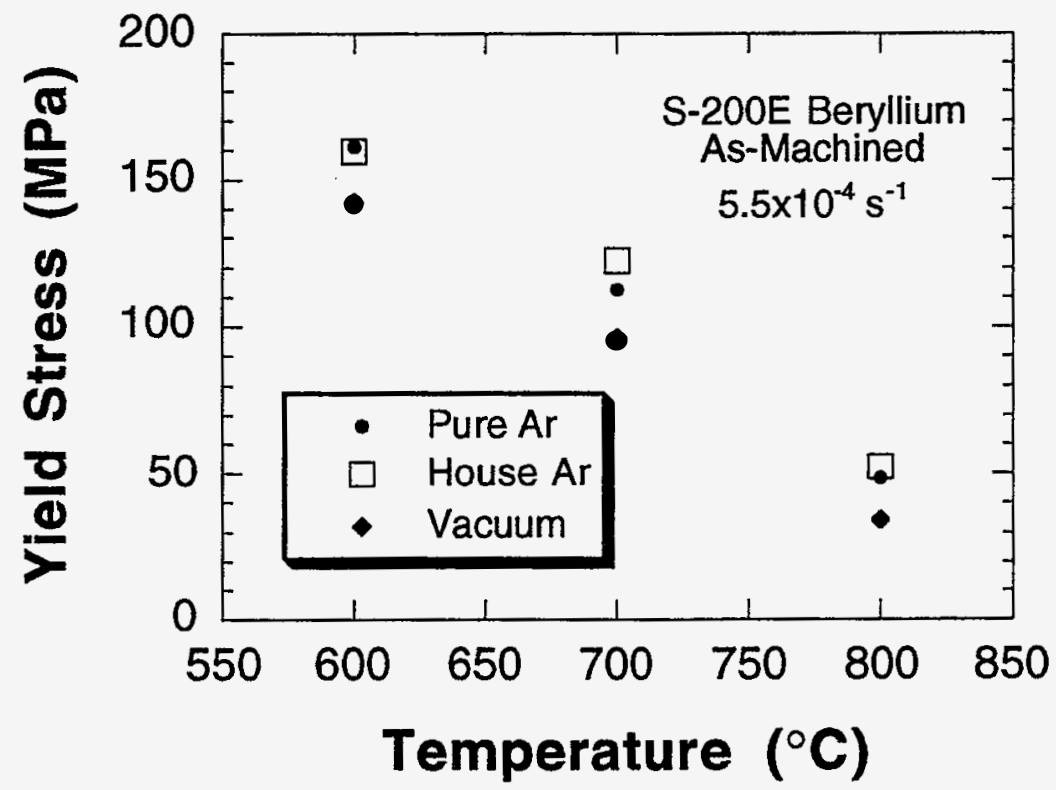

Figure 5. The effect of furnace atmosphere on the yield stress of longitudinal S-200E Be at intermediate temperatures.

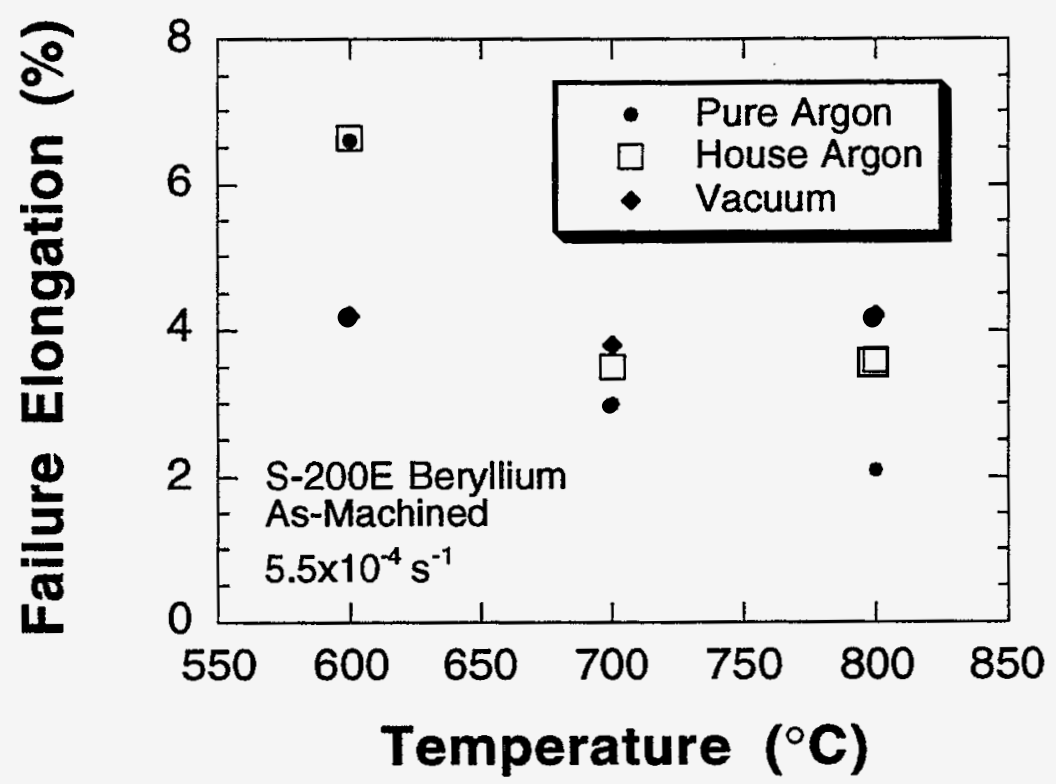

Figure 6. The effect of furnace atmosphere on the failure elongation of longitudinal $\mathrm{S}-200 \mathrm{E}$ Be at intermediate temperatures. 


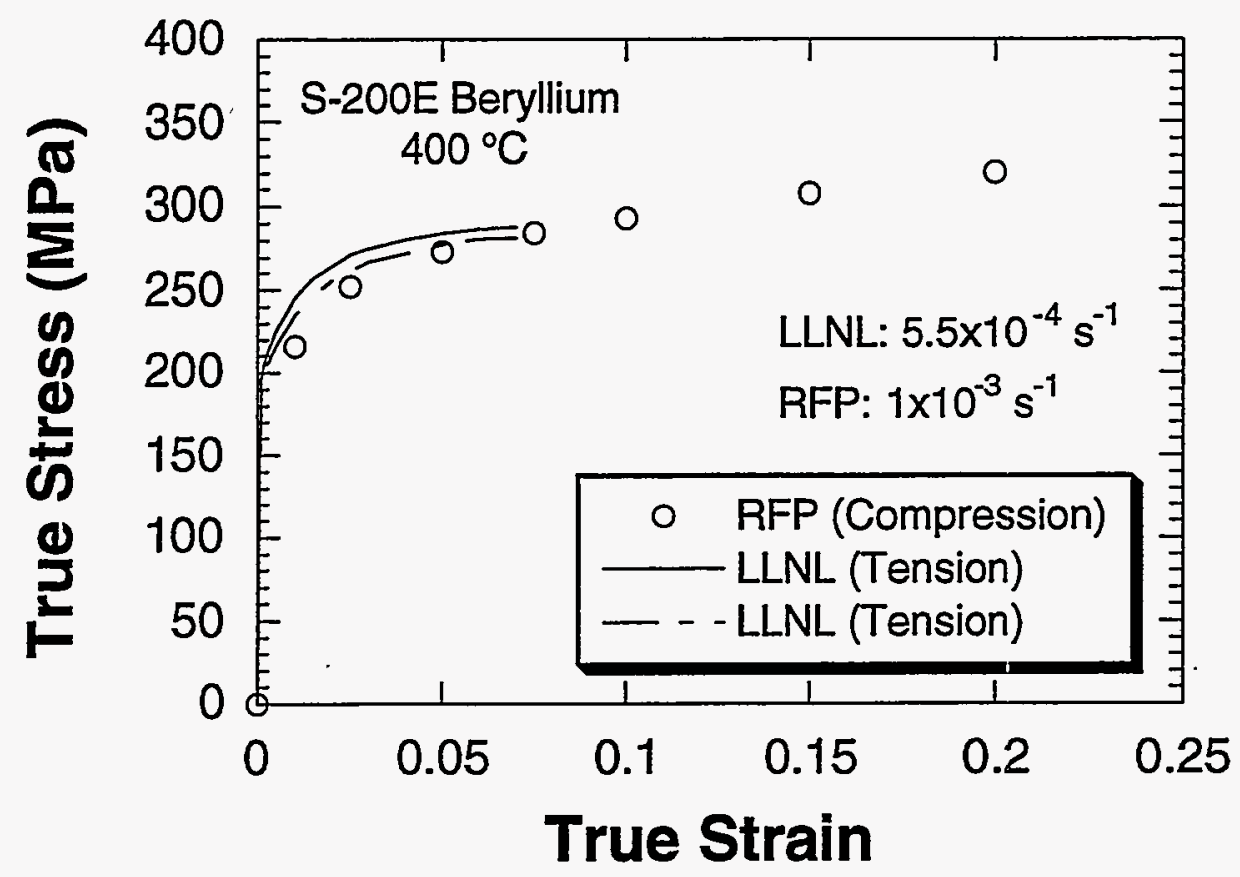

Figure 7. Comparison of the true stress vs. true strain curves in tension (present study) and compression (Abeln et al. [4]) at $400{ }^{\circ} \mathrm{C}$ and comparable strain rates.

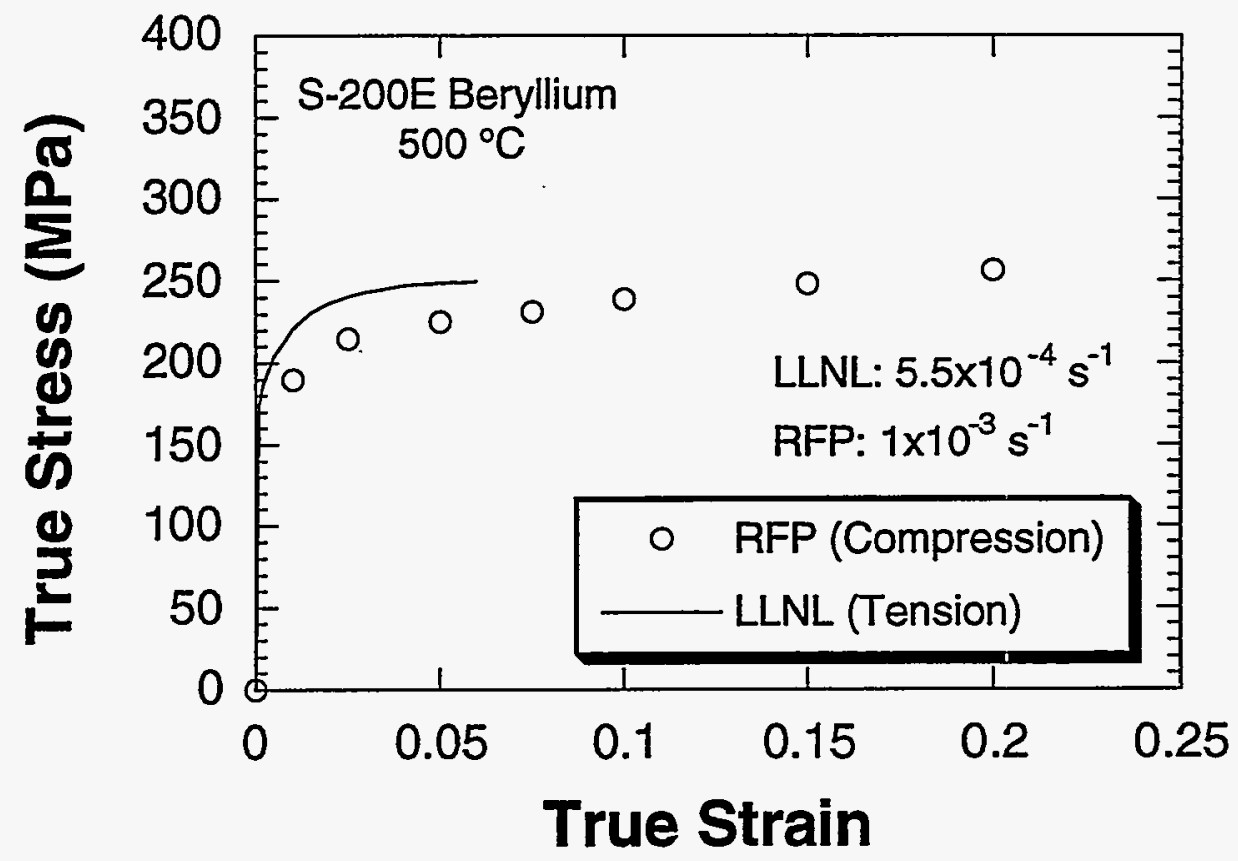

Figure 8. Comparison of the true stress vs. true strain curves in tension (present study) and compression (Abeln et al. [4]) at $500^{\circ} \mathrm{C}$ and comparable strain rates. 


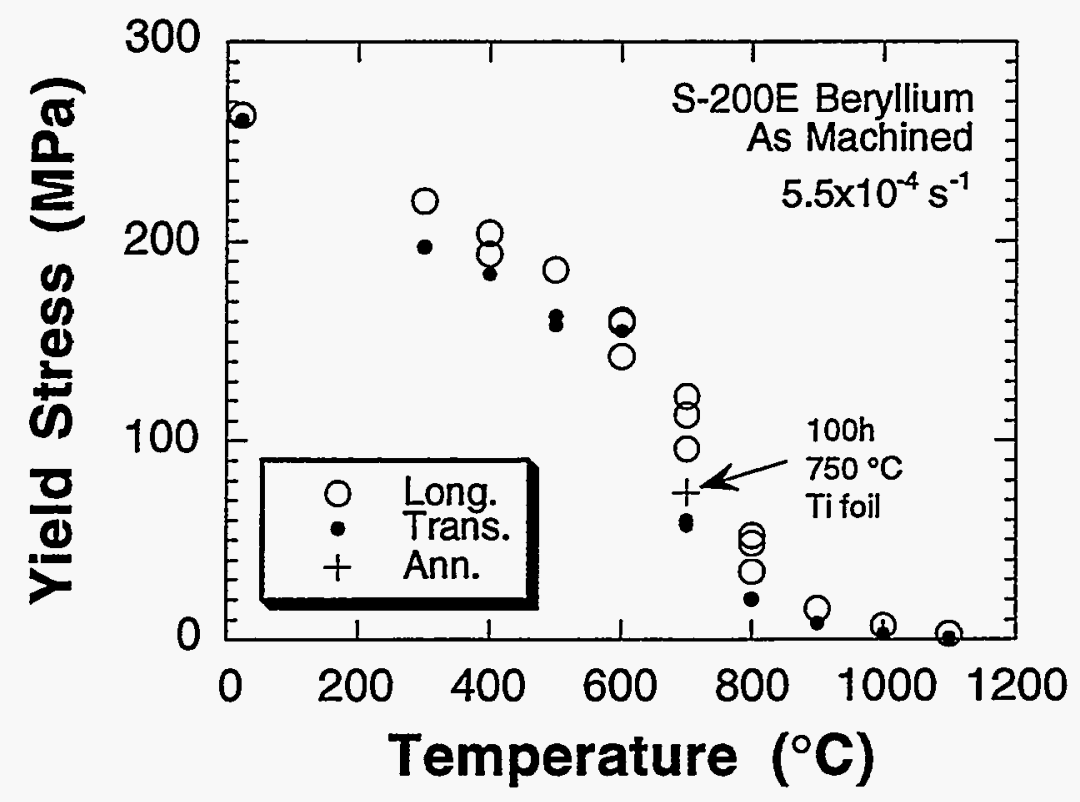

Figure 9. The $0.2 \%$-offset yield stress of S-200E beryllium as a function of test temperature for longitudinal and transverse orientations.

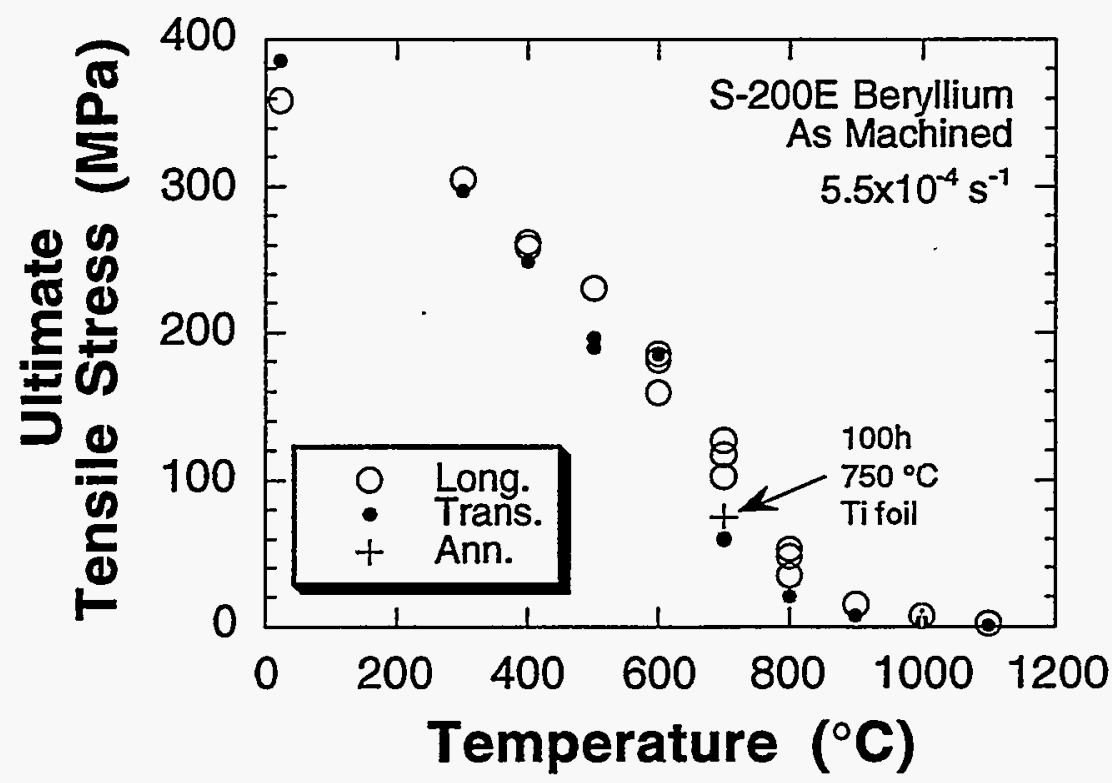

Figure 10. The ultimate tensile stress of S-200E beryllium as a function of test temperature for longitudinal and transverse orientations. 


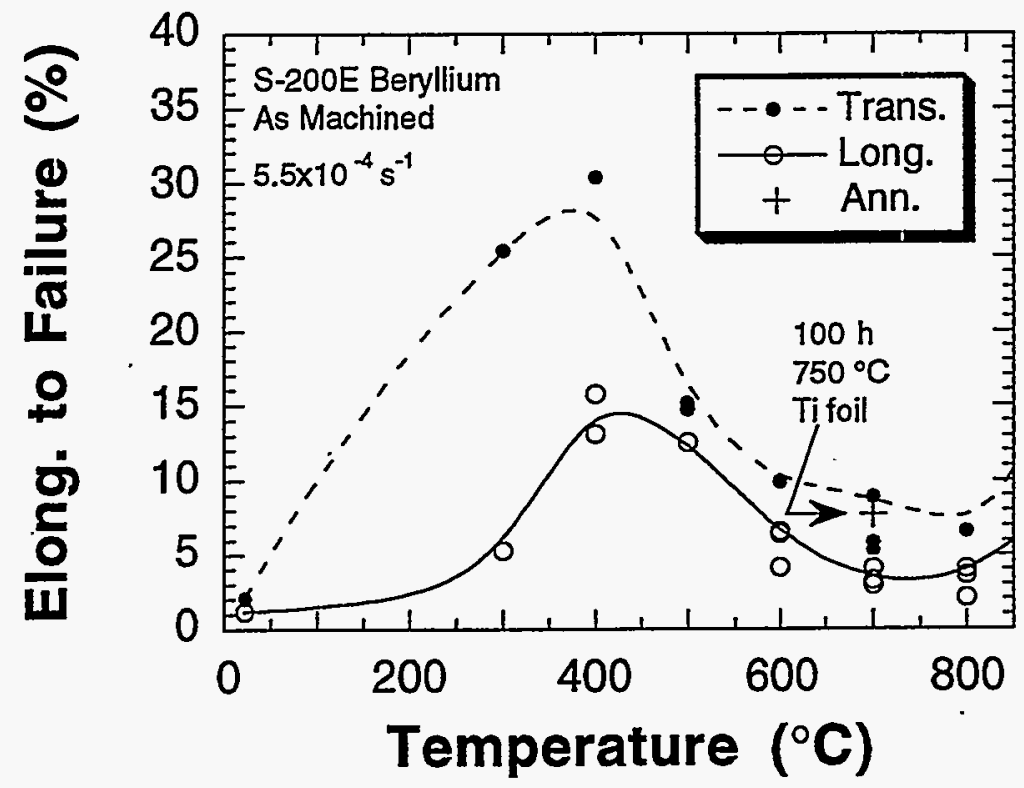

Figure 11. The elongation to failure of S-200E beryllium as a function of test temperature for longitudinal and transverse orientations. Data are shown for temperatures below $900^{\circ} \mathrm{C}$ and for a specimen annealed for $100 \mathrm{hr}$. at $750^{\circ} \mathrm{C}$.

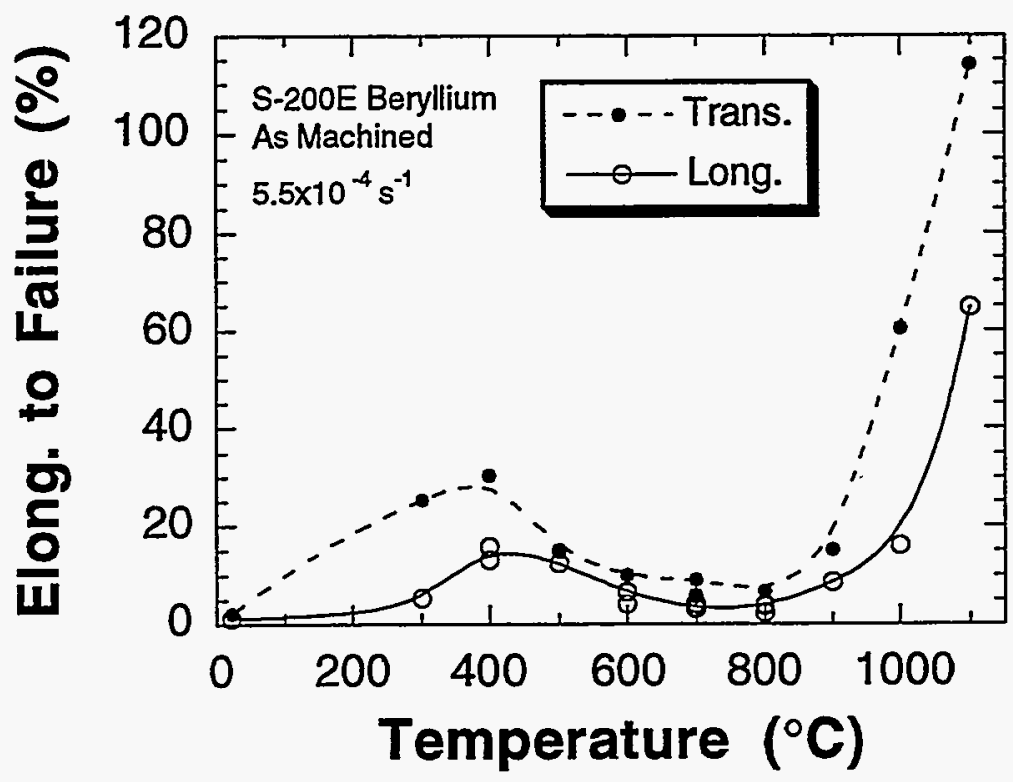

Figure 12. The elongation to failure of S-200E beryllium as a function of test temperature for longitudinal and transverse orientations. Data are shown for all temperatures tested. 


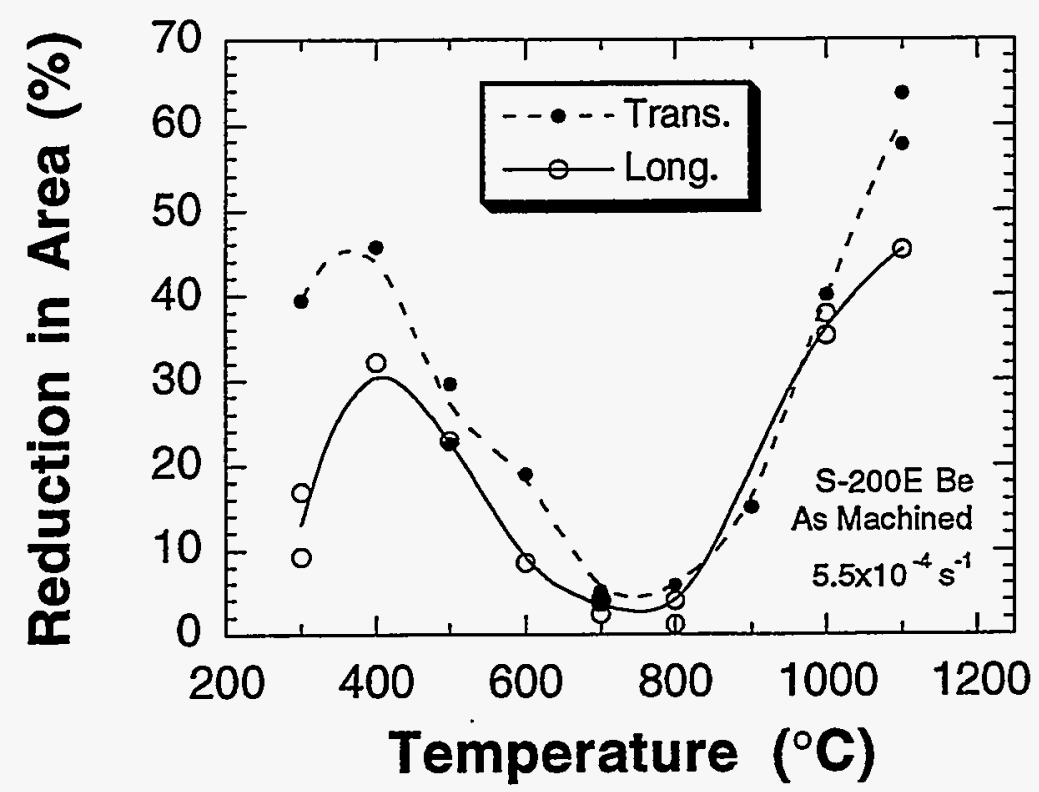

Figure 13. The reduction in area for S-200E beryllium as a function of test temperature for longitudinal and transverse orientations.

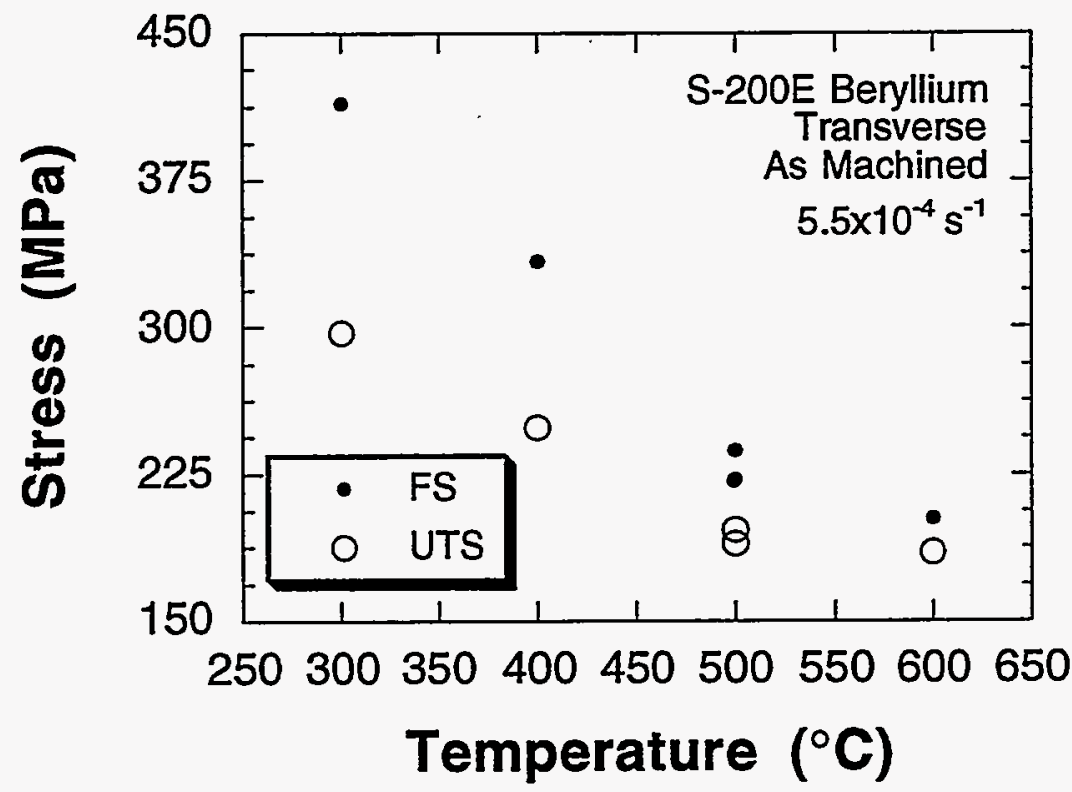

Figure 14. The fracture stress (FS) and ultimate tensile stress (UTS) are shown as a function of test temperature for S-200E beryllium in the transverse orientation. 